\title{
PENGEMBANGAN INSTRUMEN TES LITERASI SAINS PISA ASPEK MENJELASKAN FENOMENA ILMIAH KELAS VII
}

\author{
${ }^{1}$ Dwi Septiani, ${ }^{2}$ Yeni Widiyawati, ${ }^{3}$ Indri Nurwahidah \\ Program Studi Pendidikan IPA, Fakultas Sains dan Teknologi, Universitas Ivet \\ Jl. Pawiyatan Luhur IV No.17 Semarang
}

Email:wwiseptiani821@gmail.com

Article Info
Article History
Received: 16 Agustus 2019
Revised: 10 September
2019
Published: 30 September
2019
Keywords
scientific phenomena, test
instruments,
scientific literacy. PISA

\section{Informasi Artikel}

Sejarah Artikel

Diterima:

Direvisi:

Dipublikasi:

\section{Kata kunci}

Fenomena

ilmiah, instrumen tes, literasi sains PISA.

\begin{abstract}
This study aims to: (1) examine the quality of instruments based on PISA domain's scientific literacy in explaining scientific phenomena in the aspects of logical validity, (2) understanding empirical validity based on the VII grade science material development results, (3) knowing the level of scientific literacy of students of SMP N 3 Blora This research is a research and development $(R \& D)$ research using the Thiagarajan development model known as $4 D .4 D$ development consists of 4 steps, namely Define, Design, Develop, Disseminate. The research subjects of class VII students at SMP N 3 Blora discussing 98 students. Validator The questionnaire was validated by 2 expert lecturers of material, the results of the logical validity test, received $91.25 \%$ which means it was in accordance with all aspects. The test instrument was revised according to the validator's suggestion. From the results of tests on students, the results of empirical analysis obtained validity test items were 22 items valid and 8 items were invalid, with a reliability test result of 0.724 which means reliable. Difficulty test results of the test instruments were categorized as 2 difficult items, 24 moderate items and 4 easy questions. While the different power test results obtained 12 bad questions, 15 enough questions, 2 good questions and 1 negative question. Based on the validity test, empirical test instruments that were worthy of re-use were 20 questions, with poor difference but were in accordance with expert lecturers about the material that must be available to represent the material. The level of student literacy in Blora 3 N SMP overall is in the sufficient category.
\end{abstract}

\begin{abstract}
Abstrak
Penelitian ini bertujuan untuk: (1) mengkaji kualitas instrumen tes berbasis literasi sains PISA domain menjelaskan fenomena ilmiah dalam aspek validitas logis, (2) mengetahui validitas empiris berbasis literasi sains materi IPA kelas VII hasil pengembangan, (3) mengetahui tingkat literasi sains siswa SMP N 3 Blora. .Penenltian ini merupakan penlitian Research and Development (R\&D) dengan menggunakan model pengembangan Thiagarajan yang dikenal dengan 4D. Pengembangan 4D terdiri 4 tahap yaitu Define (pendefinisian), Design (perancangan), Develop (pengembangan), Disseminate (penyebarluasan). Subjek penelitian ini siswa SMP kelas VII di SMP N 3 Blora yang berjumlah 98 siswa. Angket validator divalidasi 2 dosen ahli materi, hasil uji validitas logis mendapatkan 91,25\% yang berarti sangat sesuai dengan keseluruhan aspeknya. Instrumen tes di revisi tahap awal sesuai saran validator. Berdasarkan hasil tes terhadap siswa, hasil analisis empiris didapatkan uji validitas butir soal sebanyak 22 butir soal valid dan 8 butir soal tidak valid, dengan hasil uji reliabilitas sebanyak 0,724 yang artinya reliabel. Hasil uji tingkat kesukaran instrumen tes dikategorikan 2 butir soal sukar, 24 butir soal sedang dan 4 butir soal mudah. Hasil uji daya beda didapatkan 12 butir soal jelek, 15 butir soal cukup, 2 butir soal baik dan 1 butir soal negatif. Berdasarkan uji validitas empiris instrumen tes yang layak digunakan kembali sebanyak 20 soal, dengan daya beda yang jelek namun sudah dinyatakan sesuai oleh dosen ahli materi sehingga soal tersebut harus ada untuk mewakili materi. Tingkat literasi sains siswa di SMP N 3 Blora secara keseluruhan dalam kategori cukup.
\end{abstract}


Sitasi: Septiani, Dwi. Yeni Widiyawati, Indri Nurwahidah. (2019). Pengembangan Instrumen Tes Literasi Sains Pisa Aspek Menjelaskan Fenomena Ilmiah Kelas VII. Science Education and Application Journal (SEAJ). Vol. 1 No. 2: 46 - 55.

\section{PENDAHULUAN}

Mata pelajaran IPA merupakan salah satu pelajaran wajib bagi siswa SMP yang terdapat pada kurikulum 2013. Pelajaran IPA sangat penting untuk dikuasai siswa, sebab ketika siswa menguasai materi mereka dapat menerapkannya dalam kehidupan sehari-hari. Zuriyani (2013: 2) menyatakan bahwa pembelajaran dengan proses sains dapat meningkatkan kemampuan kepada siswa di masa depan. Tindakan memahami sains serta mengaplikasikan pada kehidupan nyata disebut sebagai literasi sains. Literasi sains dapat diartikan sebagai pemahaman pengetahuan sains dan aplikasinya untuk kehidupan nyata pada masyarakat (Lestari, 2018).

Penilaian literasi sains berskala Internasional adalah Programme of International Student Assesment (PISA) dan Trends in International Mathematics and Science Study (TIMSS) yang dilakukan oleh Organization for Economic Cooperation and Development (OECD) mulai dilakukan dari tahun 2000 (Sellar \& B, 2015: 920). Indonesia berpartisipasi dalam TIMSS sejak tahun 1999 yang diikuti oleh 38 negara dan tahun 2011 anggota TIMSS sebanyak 79 negara. Skor literasi sains siswa Indonesia dalam TIMSS tahun 1999, 2003, 2007, 2011 berturut-turut 435, 420, 427 dan 406 (Mullis, et al., 2011). Literasi sains siswa Indonesia tahun 2015 berada pada urutan ke-44 dari 47 negara dengan skor 397 (Mullis, Martin, Foy, \& Hooper, 2015). Hasil PISA menunjukkan skor rata-rata literasi sains Indonesia berada di bawah raat-rata skor Internasional.

Mengkategorikan kemampuan peserta didik dalam literasi sains maka digunakan indikator dalam menentukan kemampuan literasi sains. Indikator kemampuan literasi sains dari (Gormally, Peggy, \& Mary, 2012: 365). Pengukuran indikator literasi sains tersebut berupa (1) memahami desain penelitian dan dampak terhadap penemuan/ kesimpulan; (2) melakukan penelitian literasi yang efektif; (3) mengidentifikasi kevalidan pendapat ahli; (4) membuat grafik dari data secara tepat; (5) memecahkan masalah menggunakan kuantitatif, termasuk statistik dasar; (7) melakukan prediksi dan menyimpulkan data kuantitatif. Indikator kemampuan literasi sains yang dikembangkan oleh Gormally (2012: 365) dipilih karena sangat sederhana, mudah diimplementasikan dan telah tecerminkan dari kemampuan literasi sains. Kompetensi yang diukur pada penelitian ini yaitu menjelaskan fenomena ilmiah ada pada indikator 2 sampai 6.

Pengembangan instrumen tes berbasis PISA dapat melatih kemampuan penalaran menjadi meningkat (Sinaga, 2015). Putri (2014: 167) menyatakan bahwa rendahnya penguasaan literasi sains yaitu penyebabnya guru kurang terbiasa dengan proses pembelajaran untuk mendukung siswa agar mengembangkan literasi sains. Shofiyah (2015) menyatakan bahwa kemampuan literasi sains siswa termasuk dalam kategori nominal, yaitu dapat menjawab persoalan-persoalan yang diberikan, tapi tidak menjelaskan secara ilmiah bahkan mengalami miskonsepsi. Kemampuan rendahnya literasi sains siswa sebabkan siswa belum terbiasa menjawab soal-soal literasi sains.

Berdasarkan hasil observasi di SMP Negeri 3 Blora diperoleh informasi bahwa peran guru dalam proses pembelajarannya kurang mendukung perkembangan kemampuan literasi sains siswa. Evaluasi guru menyatakan bahwa belum mengembangkan instrumen tes berbasis literasi sains. Menurut Wulandari dan Sholihin (2016) bahwa kemampuan literasi sains menggunakan bukti-bukti ilmiah hasilnya baik, sedangkan kemampuan literasi sains berbasis fenomena ilmiah masih dalam kategori cukup. Tes yang digunakan di sana hanya yang mengukur tingkat kognitif siswa saja, belum ada instrumen tes di SMP N 3 Blora yang dapat mengukur literasi sains siswa. 
Adanya predikat sekolah Adiwiyata Nasional siswa harus lebih mencintai alam dan harus mengerti fenomena-fenomena alam yang terjadi di lingkungannya. Siswa kurang memahami fenomena ilmiah di sekitarnya, maka diperlukan tindakan untuk meningkatkan peran serta siswa dalam mendukung predikat Adiwiyata Nasional. Tindakan tersebut bisa dilakukan dengan meningkatkan pemahaman siswa tentang fenomena ilmiah melalui instrumen tes yang dikembangkan. Literasi sains dapat diukur melalui pemberian soal yang diadaptasi dari dimensi PISA dan telah disesuaikan dengan kurikulum yang di terapkan di Indonesia.

Berdasarkan latar belakang dapat dirumuskan masalah sebagai berikut: (1) Apakah instrumen tes berbasis literasi sains PISA domain fenomena ilmiah menenuhi kriteria kevalidan logis? (2) Bagaimana validitas empiris instrumen tes berbasis literasi sains materi IPA kelas VII hasil pengembangan? (3) Bagaimana tingkat literasi sains siswa SMP Negeri 3 Blora? Tujuan dari penelitian ini adalah: (1) Mengkaji kualitas instrumen tes berbasis literasi sains PISA domain fenomena ilmiah dalam aspek validitas logis. (2) Mengetehui validitas empiris instrumen tes berbasis literasi sains materi IPA kelas VII hasil pengembangan. (3) Mengetahui tingkat literasi sains siswa SMP Negeri 3 Blora. Penelitian ini diharapkan dapat member manfaat terhadap berbagai pihak, diantaranya: (1) Bagi Guru: penelitian ini menjadi referensi bagi guru untuk mengembangkan intrumen tes berbasis literasi sains PISA domain fenomena ilmiah dan menjadi referensi mengenai tingkat literasi sains siswa. (2) Bagi Siswa: untuk melatih dan meningkatkan literasi sains siswa. (3) Bagi Peneliti: memberikan pengetahuan dan pengalaman dalam mengembangkan instrumen tes berbasis literasi sains dalam aspek menjelaskan fenomena ilmiah materi IPA kelas VII dan menyelesaikan tugas akhir.

\section{METODE}

\section{Jenis Penelitian}

Jenis penelitian yang digunakan adalah penelitian dan pengembangan (research and development). Model pengembangan yang digunakan dalam penelitian ini adalah 4-D yang dikembangkan oleh Thiagarajan. Model 4-D terdiri dari empat tahapan penelitian dan pengembangan, yaitu tahap pendefinisian (define), tahap perancangan (design), tahap pengembangan (develop) dan tahap penyebarluasan (disseminate) (Thiagarajan, Sammel, \& Sommel, 1974: 5).

\section{Waktu dan Tempat Penelitian}

Penelitian ini dilaksanakan pada SMP N 3 Blora diujikan ke kelas VIII. Waktu penelitian adalah 13 Juli 2019 dan 15 Juli 2019. Waktu pengerjaan instrumen tes adalah 60 menit untuk 30 soal.

\section{Populasi dan Sampel}

Populasi penelitian ini adalah siswa SMP kelas VIII di SMP Negeri 3 Blora tahun ajaran 2019/2020. Sampel dalam penelitian ini adalah untuk uji coba lapangan sebanyak 98 siswa atau 3 kelas yaitu kelas VIII F, VIII G dan VIII H.

\section{Data, Intrumen, dan Teknik Pengumpulan Data}

Teknik pengumpulan data peneliti ini yaitu dengan cara menggunakan instrumen kreativitas peserta didik. Seperti berikut:

a. Menguji kelayakan instrumen tes yang dikembangkan dengan menggunakan penilaian dari ahli yang akan membuktikan validitas isi dari instrumen yang sering disebut uji validitas empiris.

b. Melakukan uji coba instrumen tes yang dikembangkan kepada siswa SMP kelas VIII dan melihat skor yang dihasilkan untuk mengetahui kelayakan instrumen tes yang dikembangkan. 
c. Dokumentasi berupa data nilai hasil dari pengerjaan yang dilakukan siswa.

\section{Teknik Analisis Data}

\section{Analisis Logis}

Analisis yang didasarkan pada saran atau hasil validasi dari ahli materi. Penelitian ini menggunakan angket validasi skala Likert dengan 4 skala, agar mengurangi jawaban tengah atau ragu-ragu. Untuk menghitung angket validasi dengan menggunakan rumus sebagai berikut Purwanto (2011):

Dengan:

$$
\mathrm{AP}=\frac{\text { skala aktual }}{\text { skala ideal }} \times 100 \%
$$

$\mathrm{AP} \quad=$ angka persentase

Skala actual $=$ skor total validator yang sudah dirata-rata

Skala ideal $=$ skor total skala tertinggi

Tabel 1. Kriteria Uji Validator

\begin{tabular}{|l|l|}
\hline Interval & Kriteria \\
\hline $76 \%-100 \%$ & Sangat sesuai \\
\hline $51 \%-75 \%$ & Sesuai \\
\hline $26 \%-50 \%$ & Tidak sesuai \\
\hline $0 \%-25 \%$ & Sangat tidak sesuai \\
\hline
\end{tabular}

\section{Analisis Empiris}

a. Validitas Instrumen

Rumus kolerasi yang dapat digunakan adalah yang dikenal dengan rumus kolerasi product moment (Arikunto, 2015) sebagai berikut:

$$
r_{x y}=\frac{N \Sigma X Y-(\Sigma X)(\Sigma Y)}{\sqrt{\left\{N \Sigma X^{2}-(\Sigma X)^{2}\right\}\left\{N \Sigma Y^{2}-(\Sigma Y)^{2}\right\}}}
$$

Rumus diatas digunakan untuk mengukur tingkat kevalidan soal tes per butir soal. Soal dikatakan valid jika nilai $r_{\text {Hitung }}>r_{\text {Tabel, }}$, begitu sebaliknya soal dikatakan tidak valid jika nilai $\mathrm{r}_{\text {Hitung }}<\mathrm{r}_{\text {Tabel }}$ (Arikunto, 2015).

b. Reliabilitas Instrumen

Suatu tes menghasilkan tes yang tetap dapat dikatakan terpercaya yang tinggi. Pengertian reliabilitas, saling berhubungan dengan ketetapan atau keajegan hasil (Arikunto, 2015). Pada penelitian ini, rumus yang digunakan adalah

$$
\mathrm{r}_{11}=\left(\frac{\mathrm{n}}{\mathrm{n}-1}\right)\left(\frac{s^{2}-\sum p q}{s^{2}}\right)
$$

\begin{tabular}{|c|c|}
\hline $\begin{array}{c}\text { Indeks } \\
\text { Reliabilitas }\end{array}$ & Keterangan \\
\hline $\mathrm{r}_{11}>0,70$ & Reliabel \\
\hline$r_{11}<0,70$ & Tidak reliabel \\
\hline
\end{tabular}

Menurut Arikunto (2015) hasil perhitungan reliabilitas dapat diketegorikan pada Tebel 2.

c. Taraf Kesukaran

Soal baik merupakan soal yang tidak terlalu mudah atau tidak terlalu sukar. Indeks soal kesukaran 0,0 merupakan soal sukar, sebaliknya jika indeks 1,0 menunjukkan bahwa soal terlalu mudah. Arikunto (2015) menyatakan bahwa mencari rumus daya beda dengan:

$\mathrm{P}=$ indeks kesukaran

$$
\mathrm{P}=\frac{B}{J S}
$$


$\mathrm{B}$ = banyaknya siswa menjawab benar

$\mathrm{JS}=$ jumlah seluruh peserta tes

Hasil perhitungan kelayakan dikategorikan sesuai Tabel 3 menurut Arikunto (2015: 225).

Tabel 3. Klasifikasi Indeks Kesukaran
\begin{tabular}{|c|c|}
\hline $\begin{array}{c}\text { Indeks Tingkat } \\
\text { Kesukaran }(\mathrm{P})\end{array}$ & Keterangan \\
\hline $0,0-0,30$ & Sukar \\
\hline $0,31-0,70$ & Sedang \\
\hline $0,71-1,00$ & Mudah \\
\hline
\end{tabular}

d. Daya Beda

Daya pembeda adalah kemampuan sesuatu soal untuk membedakan antara siswa yang pandai (berkemampuan tinggi) dengan siswa yang boddoh (berkemampuan rendah) (Sugiyono, 2015). Pada indeks diskriminasi berkisaran antara 0,00 sampai 1,0 tetapi ada tanda negatif, yang menunjukkan jika sesuatu soal (terbalik). Rumus indeks diskriminasi (Arikunto, 2015) adalah:

$$
\mathrm{D}=\frac{B a}{J a}-\frac{B b}{J b}=\mathrm{P}_{\mathrm{A}}-\mathrm{P}_{\mathrm{B}}
$$

Klasifikasi daya beda dapat diketegorikan menjadi Tabel 4 (Arikunto, 2015).

Tabel 4. Klasifikasi Daya Beda

\begin{tabular}{|c|c|}
\hline $\begin{array}{c}\text { Klasifikasi } \\
\text { Daya Beda }\end{array}$ & Keterangan \\
\hline $0,00-0,20$ & Jelek \\
\hline $0,21-0,40$ & Cukup \\
\hline $0,41-0,70$ & Baik \\
\hline $0,71-1,00$ & Baik Sekali \\
\hline
\end{tabular}

\section{Kategori Tingkat Literasi Sains}

Literasi sains siswa dapat dikategorikan dengan rata-rata keseluruhan nilai siswa. Nilai rata-rata diukur dengan menggunakan rumus (Arikunto, 2015):

$$
\text { Tingkat Literasi }=\frac{\text { Skor total }}{\text { Skor total tertinggi }} \times 100
$$

Dengan skala yang dikategorikan pada Tabel (Arikunto, 2015).

Tabel 5. Kategori Tingkat Nilai Siswa
\begin{tabular}{|c|c|c|}
\hline No. & Angka & Keterangan \\
\hline 1. & $80-100$ & Baik sekali \\
\hline 2. & $66-79$ & Baik \\
\hline 3. & $56-65$ & Cukup \\
\hline 4. & $40-55$ & Kurang \\
\hline 5. & $30-39$ & Gagal \\
\hline
\end{tabular}

\section{HASIL DAN PEMBAHASAN (12pt)}

\section{Analisis Logis}

Hasil validasi 2 dosen ahli materi didapatkan angka persentase sebesar 91,25\% yang artinya sangat sesuai. Untuk skor rata-rata dosen ahli 1 dan 2 dapat dilihat pada Tabel 6. 
Tabel 6. Penilaian Kesesuain Instrumen Tes

\begin{tabular}{|c|c|c|c|c|}
\hline No. & Aspek & $\begin{array}{c}\text { Rata-rata } \\
\text { Skor Ahli } 1\end{array}$ & $\begin{array}{c}\text { Rata-rata } \\
\text { Skor Ahli } 2\end{array}$ & Skor Rata-rata \\
\hline 1. & Materi & 3,83 & 3,67 & 3,75 \\
\hline 2. & \begin{tabular}{|l|} 
Literasi \\
Sains \\
\end{tabular} & 3,5 & 3,75 & 3,625 \\
\hline 3. & Konstruksi & 3,25 & 4 & 3,625 \\
\hline 4. & Bahasa & 3,5 & 3,67 & 3,585 \\
\hline \multicolumn{2}{|r|}{$\sum$ Skor } & 14,08 & 15,09 & 14,585 \\
\hline \multicolumn{2}{|c|}{ Rata-rata Skor } & 3,52 & 3,7725 & 3,646 \\
\hline \multicolumn{2}{|r|}{ Kriteria } & $\begin{array}{l}\text { Sangat } \\
\text { sesuai }\end{array}$ & Sangat sesuai & Sangat sesuai \\
\hline
\end{tabular}

Berdasarkan Tabel 6 menunjukkan bahwa instrumen tes yang dikembangkan menurut para ahli materi sangat sesuai. Adawiyah dan Wisudawati (2017) menyatakan bahwa suatu instrumen tes dikatakan sesuai apabila penilaian keseluruhan aspek yaitu aspek materi, literasi sains, konstruksi dan tata bahasa oleh para ahli baik. Sehingga instrumen tes yang dikembangkan dapat digunakan sebagai penunjang dalam memvariasikan instrumen tes pada pembeljaran IPA.

Hasil uji validator didapatkan saran yang dapat dilihat pada Tabel 7.

Tabel 7. Saran Validator

\begin{tabular}{|l|l|l|}
\hline No & \multicolumn{1}{|c|}{ Bagian Yang Perlu Direvisi } & \multicolumn{1}{c|}{ Nomor Soal } \\
\hline 1. & $\begin{array}{l}\text { Perbaiki kalimat yang kurang } \\
\text { efektif. }\end{array}$ & $2,3,10,11,12,23$ \\
\hline 2. & Kesalahan ketik. & $9,10,14,16,19,22,23,24,27,29$ \\
\hline 3. & $\begin{array}{l}\text { Cari gambar yang menggunakan } \\
\text { bahasa Indonesia. }\end{array}$ & 15,16 \\
\hline 4. & $\begin{array}{l}\text { Perbaiki letak tanda titik dan } \\
\text { koma dalam kalimat. }\end{array}$ & 4,23 \\
\hline
\end{tabular}

\section{Analisis Empiris}

a. Uji Validitas

Analisis validitas digunakan untuk mengetahui valid tidaknya item tes. Hasil uji instrumen tes didapatkan hasil pada Tabel 8.

Tabel 8. Distribusi Indeks Validitas

\begin{tabular}{|l|l|l|l|}
\hline Indeks Validitas & Butir Soal & Jumlah & Persentase \\
\hline$>0,197$ (valid) & $\begin{array}{l}1,2,3,4,5,7,8,10,11,12,14,15, \\
18,19,20,21,22,24,25,27,28\end{array}$ & $73,33 \%$ \\
\hline$<0,197$ (tidak valid) & $6,9,13,16,23,26,29,30$ & 8 & $26,67 \%$ \\
\hline
\end{tabular}

Hasil uji validitas instrumen tes pada siswa diperoleh 22 butir soal valid dan 8 butir soal tidak valid. Sejalan dengan penelitian yang dilakukan oleh Ekawati (2015) yang menunjukkan bahwa berdasarkan $70 \%$ dari instrumen tes yang kembangkan telah valid dan memenuhi kriteria instrumen tes yang baik. Instrumen tes dalam penelitian ini merupakan soal yang baik menurut validitasnya.

b. Uji Reliabilitas

Uji reliabilitas digunakan untuk mengetahui tingkat konsistensi instrumen. Instrumen yang baik secara akurat akan memberikan hasil pengukuran yang sama serta 
memiliki jawaban yang konsisten untuk kapanpun instrumen tersebut digunakan. Hasil uji reliabilitas dapat dilihat pada Tabel 9.

Tabel 9. Reliabilitas Tes

\begin{tabular}{|c|c|c|}
\hline Indeks Reliabel & $\mathbf{r}_{11}$ & Keterangan \\
\hline$>0,7$ (Reliabel) & 0,724 & Reliabel \\
\hline
\end{tabular}

Widodo (2015) menyatakan bahwa reliabilitas alat penilaian menunjukkan keajegan alat tersebut dalam menilai apa yang dinilainya. Setelah instrumen tes direvisi berdasarkan saran dan masukan dari validator, hasil uji reliabilitas sebesar 0,724. Dengan demikian, tes yang dikembangkan telah memenuhi syarat bahwa suatu soal dikatakan memiliki reliabilitas yang baik jika lebih dari 0,70 (Arikunto, 2015).

c. Uji Tingkat Kesukaran

Tingkat kesukaran digunakan untuk mengetahui tingkat kesukarannya suatu instrumen tes. Berdaskan uji tingkat kesukaran hasilnya dapat dilihat pada Tabel 10.

Tabel 10. Hasil Uji Tingkat Kesukaran

\begin{tabular}{|c|l|c|c|}
\hline $\begin{array}{c}\text { Status Tingkat } \\
\text { Kesukaran }\end{array}$ & \multicolumn{1}{|c|}{ Butir Soal } & \multicolumn{1}{|c|}{ Jumlah } & Persentase \\
\hline Sukar & 12,15 & 2 & $6,67 \%$ \\
\hline Sedang & $\begin{array}{l}1,3,4,5,6,7,8,10,11,13,14,15,16,17, \\
18,19,20,23,24,26,27,28,29,30\end{array}$ & 24 & $80 \%$ \\
\hline Mudah & $2,9,21,23$ & 4 & $13,33 \%$ \\
\hline
\end{tabular}

Hasil dari Tabel 10 dapat disimpulkan bahwa instrumen soal termasuk dalam kategori soal baik. Hal ini didukung dengan Arikunto (2015: 222) bahwa soal yang baik adalah soal yang tidak terlalu mudah dan tidak terlalu sukar.

d. Uji Daya Beda

Daya beda merupakan kemampuan suatu soal untuk membedakan antara siswa yang berkemampuan tinggi dengan siswa berkemampuan rendah (Arikunto, 2015: 226). Hasil uji daya beda dalam penelitian ini dapat dilihat pada Tabel 11.

Tabel 11. Hasil Uji Daya Beda

\begin{tabular}{|l|l|l|}
\hline Daya Beda & Butir Soal & Jumlah \\
\hline Jelek & $1,2,6,9,11,13,16,21,23,26,27,30$ & 12 \\
\hline Cukup & $4,5,7,8,10,14,15,17,18,19,20$ & 15 \\
\hline Baik & 3,12 & 2 \\
\hline Negatif & 29 & 1 \\
\hline
\end{tabular}

Berdasarkan Tabel 11 ada 1 soal yang menunjukkan hasil negatif, sesuai dengan Arikunto (2015) apabila indeks diskriminasi menunjukkan angka negatif berarti soal tersebut tidak memiliki daya pembeda. Berdasarkan uji empiris yang dilakukan dapat disimpulkan bahwa soal yang baik adalah 17 soal 3 soal tetap dipertahankan untuk digunakan kembali agar mempermudah penilaian dan soal tersebut mewakili materi. Soal yang sudah direvisi berarti sudah baik untuk mengukur literasi sains siswa. Yuliati (2017) menyatakan bahwa penilaian literasi sains tidak hanya berorientasi sains dalam situasi nyata akan tetapi juga dalam penguasaan kecakapan hidup. Nofiana dan Julianto (2018) menyatakan bahwa pembelajaran yang relevan dapat membangun kesadaran siswa akan pentingnya sains dalam menentukan karir dan sebagai anggota masyarakat.

\section{Kategori Tingkat Literasi Sains}

Tingkat literasi sains siswa di SMP N 3 Blora berdasarkan hasil uji coba dengan instrumen tes didapatkan dalam kategori cukup. hasil uji menunjukkan 59 yang artinya 
secara keseluruhan dalam kategori cukup. Kategori literasi sains siswa berdasarkan hasil tes individu dapat dilihat pada Gambar 1.

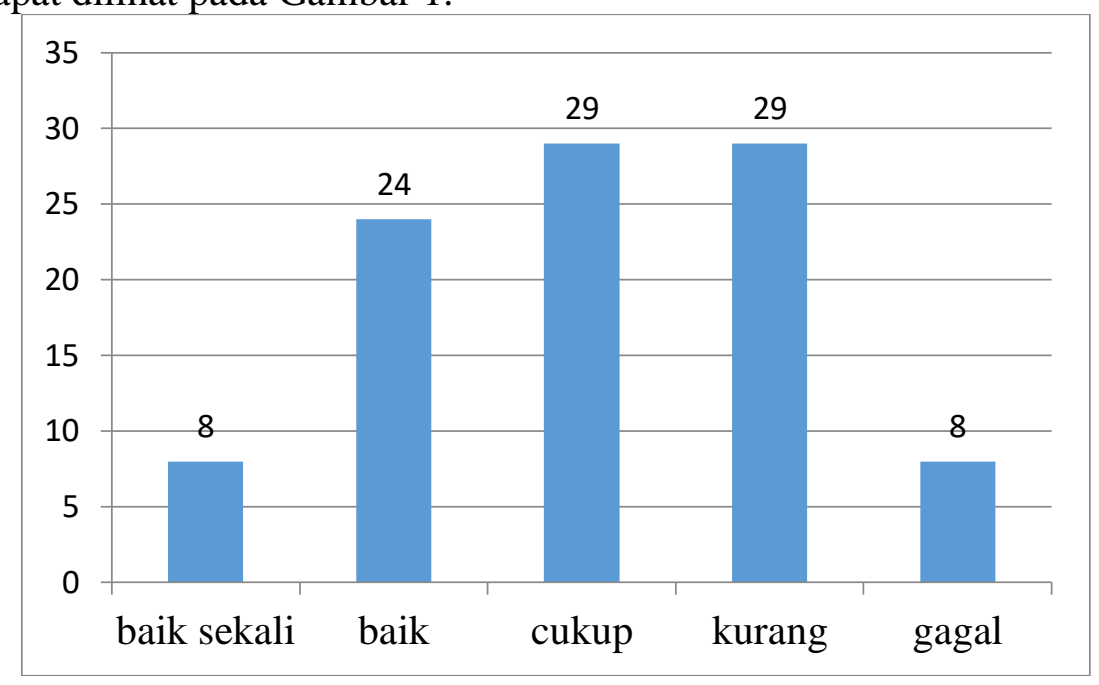

Gambar 1. Kategori Literasi Sains

Nofiana dan Julianto (2018) menyatakan bahwa penyebab rendahnya literasi sains siswa menjadi kurang tanggap terhadap perkembangan dan permasalahan yang ada di sekitar lingkungan berkaitan dengan fenomena alam, keunggulan lokal daerah, maupun permasalahan yang ada di lingkungan sekitar. Menurut OECD (2015) banyak faktor yang menyebabkan rendahnya literasi sains di Indonesia diantaranya gender, ekonomi dan sosial. Sesuai dengan Andriani (2018) dalam penelitian ini dapat disimpulkan bahwa tingkat literasi sains siswa dipengaruhi oleh wilayah sekolah dan tempat tinggal siswa.

Hasil uji coba pengembangan yang telah dilakukan menghasilkan 30 instrumen tes, sedangkan yang layak digunakan kembali 20 soal. Hasil yang lebih jelas dapat dilihat pada Tabel 12.

Tabel 12. Produk Akhir

\begin{tabular}{|c|c|c|c|}
\hline Nomor Butir Soal & Validitas Tes & Tingkat Kesukaran & Daya Beda \\
\hline 2 & Valid & Mudah & Jelek \\
\hline 3 & Valid & Sedang & Baik \\
\hline 4 & Valid & Sedang & Cukup \\
\hline 5 & Valid & Sedang & Cukup \\
\hline 7 & Valid & Sedang & Cukup \\
\hline 8 & Valid & Sedang & Cukup \\
\hline 10 & Valid & Sedang & Cukup \\
\hline 12 & Valid & Sukar & Baik \\
\hline 14 & Valid & Sedang & Cukup \\
\hline 15 & Valid & Sukar & Cukup \\
\hline 17 & Valid & Sedang & Cukup \\
\hline 18 & Valid & Sedang & Cukup \\
\hline 19 & Valid & Sedang & Cukup \\
\hline 20 & Valid & Sedang & Cukup \\
\hline 21 & Valid & Mudah & Jelek \\
\hline 22 & Valid & Mudah & Cukup \\
\hline 24 & Valid & Sedang & Cukup \\
\hline 25 & Valid & Sedang & Cukup \\
\hline 27 & Valid & Jelek & Cukup \\
\hline 28 & Valid & Sedang & Cukup \\
\hline
\end{tabular}




\section{KESIMPULAN}

Instrumen tes berbasis literasi sains pada SMP N 3 Blora didapatkan hasil sebagai berikut: (1) Instrument tes berbasis literasi sains PISA domain menjelaskan fenomena ilmiah memenuhi validitas logis, yaitu berdasarkan uji validasi didapatkan hasil rata-rata skor ahli 73 atau $91,25 \%$ berarti dalam kategori sangat sesuai. (2) Validitas empiris berbasis literasi sains materi IPA kelas VII setelah diimplementasikan kepada siswa didapatkan hasil validitas 22 butir soal valid dan 8 soal tidak valid, dengan nilai hasil uji reliabilitas 0,724 . Daya beda didapatkan soal kategori jelek 12 butir, kategori cukup 15 butir, soal kategori baik 2 butir dan 1 butir soal negatif. Tingkat kesukaran dikategorikan menjadi soal sukar 2 butir, soal sedang 24 butir soal dan soal mudah 4 butir soal. Berdasarkan uji empiris instrumen tes diperoleh produk akhir yaitu instrumen tes yang layak digunakan kembali yaitu sebanyak 20 soal. (3) Tingkat literasi sains siswa di SMP Negeri 3 Blora domain menjelaskan fenomena ilmiah termasuk dalam kategori cukup berdasarkan pengukuran dengan instrumen tes yang dikembangkan.

\section{SARAN}

Berdasarkan hasil penelitian, maka dapat diberikan beberapa saran antara lain :

1. Dalam mengukur literasi sains siswa, instrumen tes ini dapat digunakan sebagai alat ukur yang reliabel.

2. Perlu dilakukan penelitian lanjutan untuk menguji keefektivan instrumen tes berbasis literasi sains PISA domain menjelaskan fenomena ilmiah pada materi interaksi makhluk hidup dengan lingkungan, pencemaran lingkungan dan tata surya.

3. Berdasarkan hasil penelitian disarankan untuk melakukan inovasi pembelajaran untuk meningkatkan literasi sains.

\section{UCAPAN TERIMA KASIH}

Universitas Ivet, Program Studi Pendidikan IPA, dosen Pembimbing I dan II.

\section{DAFTAR PUSTAKA}

Adawiyah, R., \& Wisudawati, A. (2017). Pengembangan instrumen tes berbasis literasi sains. Indonesia Jornal of Curriiculum and Education Technology Studies Vol 5 No 2 , 112121.

Andriani, N., Saparini, \& Akhsan, H. (2018). Kemampuan literasi sains fisika siswa SMP kelas VII di Sumatra Selatan menggunakan kerangka PISA. Berkala ilmiah pendidikan fisika Vol 6 No 3 , 278-291.

Arikunto, S. (2015). Dasar-dasar evaluasi pendidikan. Jakarta: Bumi Aksara.

Ekawati, F. (2015). Analisis butir soal ulangan akhir semester gasal akutansi perusahaan dagang. Jurnal KPAI Vol 4 No 2 , 25-37.

Gormally, C., Peggy, B., \& Mary, L. (2012). Developing a test of scientific literacy skills (TOLS): measuring pundergraduates evaluation of scientific information and arguments. CBE-Life Sciences Education Vol 1 No1 , 364-377.

Lestari, S. P. (2018). Analisis literasi sains mahasiswa program studi pendidikan biologi raden intan Lampung. UIN Raden Intan Lampung .

Mullis, I. V., Martin, M. O., Foy, P., \& Hooper, M. (2015). TIMSS advanced 2015 international result in advanced mathematics and physics. International Study Center . 
Mullis, I. V., Martin, M. O., Minnich, C. A., Stanco, G. M., Arora, A., Centurino, V. A., et al. (2011). Education policy and curriculum in mathematics and science. TIMSS Encyclopedia, A-K.

Nofiana, M., \& Julianto, T. (2018). Upaya peningkatakan literasi sains siswa melalui pembelajaran berbasis keunggulan lokal. BIOSFER Jurnal Tadris Pendidikan Biologi Vol 9 No 1 , 24-35.

OECD. (2015). PISA 2015 results in focus. New York: Columbia University.

Purwanto. (2011). Evaluasi hasil belajar. Yogyakarta: 121.

Putri, A. E. (2014). Kemampuan penalaran siswa kelas X IPA SMA terkait dengan konsep biologi. 159-189.

Sellar, S., \& B, L. (2015). The OECD and the expansion of PISA : New Global Modes of Govermence in Education. Britsh Educational Research Journal Vol 40 No 6 , 917-936.

Shofiyah, N. (2015). Deskripsi literasi sains awal mahasiswa pendidikan IPA pada konsep IPA. Journal Pedagogia ISSN 2089-3833 Volume 4 No 2 , 113-120.

Sinaga, T. N. (2015). Pengembangan soal model PISA mata pelajaran ilmu pengetahuan alam terpadu konten fisika untuk mengetahui penalaran siswa kelas IX. Jurnal Inovasi dan Pembelajaran Fisika Volume 2 Nomor 2 , 194-197.

Sugiyono. (2015). Metode penelitian pendidikan pendekatan kuantitatif, kualitatif dan $R \& D$. Bandung: Alfabeta.

Thiagarajan, S., Sammel, D. S., \& Sommel, M. I. (1974). Instructional development for training teacher of exceptional children. Washinton DC: National Center for Improvement Educational System.

Widodo, P. B. (2015). Reliabilitas dan validitas konstruk skala konsep diri untuk mahasiswa Indonesia. Journal psikologi universitas diponegoro Vol 3 No 1, 1-9.

Yuliati, Y. (2017). Literasi sains dalam pembelajaran IPA . Jurnal Cakrawala Pendas Vol 3 No $2,21-28$.

Zuriyani, E. (2013). Literasi sains dan pendidikan. Sumsel Kemenag , 1-10. 